\title{
Psychological vulnerability among adolescent offspring of parents with mental illness
}

\author{
Rani Srivastava ${ }^{1 *}$, Alka Sabharwal ${ }^{2}$, Sadanandan Unni $^{3}$, Parul Gairola ${ }^{3}$, Anita Tyagi ${ }^{4}$ \\ ${ }^{\mathbf{1}}$ Professor \& Head, ${ }^{\mathbf{1},-5}$ Dept. of Clinical Psychology, ${ }^{\mathbf{2}}$ Dept. of Statistics, ${ }^{\mathbf{1}, \mathbf{3}-5}$ Santosh Medical College and Hospital, Ghaziabad, Uttar \\ Pradesh, ${ }^{2}$ Kirori Mal College, University of Delhi, Delhi, India
}

*Corresponding Author: Rani Srivastava

Email: drrani8856@gmail.com

\begin{abstract}
Introduction: It is important that mental health and social services support are rendered for the parent and to their children both who have mental health problem. Researches have shown that some children of parents with a severe and enduring mental illness experience greater levels of emotional, psychological and behavioural problems than children and young people in the rest of the population apart from genetic factors are known causes of mental illness.

Aims and Objectives: Keeping this idea in mind this study has been conducted to screen out the psychological disturbances among adolescent offspring of parents with mental illness \& adolescent offspring of parent with normal health.

Materials and Methods: This study a cross sectional, prospective \& comparative study. Sample- 58 Subjects of study were adolescent offspring belonging to the age between 15-18 years. Test Measures: GHQ, BPRS, SSCT, AISS \& SASS.

Results \& Discussions: The results have screened out significant psychological disturbances like; psychiatric complaints, interpersonal disturbances in \& outside family, adjustment issues \& problems in their attitudes among the adolescent offspring of psychologically disturbed parent (Study) in comparison to the adolescent offspring of parents with normal well-being (control).

Conclusion and Recommendation: The results have shown significant problem among the offspring of psychologically disturbed parent (study) in comparison to the adolescent offspring of parents with normal well-being (control). Findings are very encouraging for every professional in this particular area \& for society as a whole.
\end{abstract}

Keywords: Personality, Psychological Vulnerability, Interpersonal relations, Attitude \& adolescent offspring.

\section{Introduction}

Mental health problems (MHP) of parents are associated with risk of psychological and developmental difficulties in their offspring, Mc Laughlin et al. (2012) ${ }^{1}$ which is even 1.8 to 2.9 times higher \& when it is compared with the total population if one parent was affected, rising to a risk of 2.2 to 4.6 times higher if both parents are affected ${ }^{2}$ for the development of MHP. The family unit is the single most important variable in the onset, progression, treatment and outcome of psychiatric illnesses or mental disorders. Various researches as well as theoretical formulations have been explored to understand the role of family pathology in the causation (genesis) and maintenance of mental disorders. Even drug dependence and alcohol addictions also can be long term causes for mental health dysfunctions. Many offspring live with a parent who have a long-term alcohol or drug dependence, sometimes it is combined with a mental problem. Researches have shown that some children of parents with a severe and enduring mental illness experience greater levels of emotional, psychological and behavioural problems than children and young people in the rest of the population apart from genetic factors are known causes of mental illness. Keeping this idea in mind this study has been planned and conducted.

Adolescence is viewed as a transitional period between childhood and adulthood, whose cultural purpose is the preparation of children for adult roles. It is a period of multiple transitions involving education, training, employment and unemployment, as well as transitions from one living circumstance to another. Today's adolescents face multiple challenges which are quite different from those faced by their parents during their adolescence. Now-a-days every adolescent is found to be under stress due to variety of reasons \& if by chance their parent's mental health is afflicted, it acts as an additive factor for such offspring.

Now, the question is in what ways psychological disturbances of adolescent offspring are perceived. Studies reported at national and international platform that very less attention has been paid to know about the psychological disturbances among adolescents Even Indian studies Anant and Sarit (2013), ${ }^{3}$ Jagdish Varma, Sandhya and Jayshree et.al. $(2017)^{4}$ have also accepted that mental health problems belonging to either rural or urban adolescence are inadequately researched in our setting sand the investigation into the mental health status of the adolescent offspring of mentally ill parents is having more restricted \& inadequate findings. It is a time-tested assumption that having a person with mental illness in the family is stressful for all the family members especially for the growing adolescents. In our opinion instead of simply looking after the mental health of the adolescents, more weightage should be given for the adolescents who have psychologically disturbed parents. It is also noted that the age of adolescence is considered to be of emotional turmoil, and the presence of parental mental illness is definitely a negative factor. With the same notion we tried to aim at this topic.

Through this study an effort has been made to take care of this ignored population, who had not been adequately attended to. It is our fundamental right to enjoy normal health. Our country is still in a state of unmoved condition beyond clinical description. ${ }^{5}$ 


\section{Materials and Methods}

An observational cross-sectional study. The parents, whose adolescent offspring were taken for study, were registered patients in IPD of department of Psychiatry, Lady Hardinge Medical College (L.H.M.C.), New Delhi, India from October 2013 to September 2015. Study subjects were adolescent offspring of those parents who were suffering from mental disorder / alcohol abuse \& were under treatment for their mental illness. The number of parents enrolled within the said period was 61. Out of 61 afflicted parents the offspring of three parents were not matching with age group of this study. Rest 58 parents whose adolescent offspring were taken for study purpose. This study included 116 adolescents' in the age group of 15 to 18 years, categorized in two groups (Study $\&$ controlled), each of size 58, in accordance with the inclusion and exclusion criteria for the present study. A written consent was obtained from each subject. The method of sampling for the Study group was purposive because the subjects were the offspring of mentally ill parents who were available when they used to visit the said department for their parent's treatment.

To screen out the psychological disturbances among adolescent offspring (Study group) of parents with mentally illness \& parents with normal health in relation their general health, psychiatric disturbances, inter-personal relations within family and outside, adjustment capacities at emotional, social and educational level, adolescents' attitude towards their teachers and parents, discipline, life \& humanity, country and religion. (As a whole, gender wise, age wise and socio-economic status wise). Study group' subjects included in the study were the adolescents of age group between 15 to18 years of psychiatrically ill parents utilizing the services of the Department of Psychiatry, Lady Hardinge Medical College, N Delhi. Control Group's subjects included were the adolescents of age group between
15 to 18 years of healthy (without any psychiatric problem) parents who were selected from a New Delhi Municipal Corporation (NDMC) School, New Delhi. The adolescents were matched on the basis of socio-economic status, age, gender and educational level. The diagnosis of parents (either / both) was based on ICD-10 criteria \& only those parents' offspring were taken in study who were willing to participate as per consented by their parents / guardian relatives. Subjects with history of head injury with neuro-organic consequences were also excluded.

\section{Procedure}

After identifying the 58 afflicted parents with mental illness as per ICD (International classification of diseases)- $10^{\text {th }}$ revision (1994), ${ }^{6}$ their offspring were contacted in the said department where after collecting their demographic details $\&$ educational background all the selected psychological measures were applied on regular basis as per informed written consent $\&$ their routine feasibility. For controlled group the testing was done in respective schools preferably in their classroom in group setting. Considering the ethics behind psychological testing, their test findings were kept confidential for both Study \& controlled group. The testing was started after filling the Performa for demographic details. After collecting the data effect of gender, age and income were also observed. The test measures used in this study were self-administered \& self -rated tools namely; general health questionnaire (GHQ), brief psychiatric rating scale (BPRS), sack's sentence completion test (SSCT), adjustment inventory for school students (AISS) \& Sodhi attitude scale for school students (SASS). Besides test of socio-economic status by Kupposwamy was also applied. Findings were analysed on the basis of mean (M), standard deviation (SD), permutation test for (Comparing two independent groups).

Table 1: GHQ- Frequency Table for the 'Control' and 'Study' groups

\begin{tabular}{|l|c|c|c|}
\hline S. No. & Score & Study Group & Control Group \\
\hline 1 & 0 & 0 & 2 \\
\hline 2 & 1 & 0 & 2 \\
\hline 3 & 2 & 12 & 7 \\
\hline 4 & 3 & 33 & 25 \\
\hline 5 & 4 & 3 & 1 \\
\hline 6 & 5 & 2 & 2 \\
\hline 7 & 6 & 2 & 8 \\
\hline 8 & 7 & 1 & 2 \\
\hline 9 & 8 & 4 & 3 \\
\hline 10 & 9 & 1 & 5 \\
\hline 11 & 10 & 0 & 1 \\
\hline
\end{tabular}

Table 2: BPRS- Frequency Table for the 'Control' and the 'Study' groups

\begin{tabular}{|l|c|c|c|}
\hline S. No. & Score & Study Group & Control Group \\
\hline 1 & $18-36$ & 1 & 57 \\
\hline 2 & $36-54$ & 10 & 1 \\
\hline 3 & $54-72$ & 25 & 0 \\
\hline 4 & $72-90$ & 19 & 0 \\
\hline 5 & $90-108$ & 3 & 0 \\
\hline 6 & $108-126$ & 0 & 0 \\
\hline 7 & $126-144$ & 0 & 0 \\
\hline
\end{tabular}


Table 3: Item wise-descriptive statistics $(\mathrm{N}=116)$ for control, study and the combined groups

\begin{tabular}{|c|c|c|c|c|c|c|c|}
\hline \multirow[t]{2}{*}{ Attribute } & \multirow[t]{2}{*}{ Item } & \multicolumn{3}{|c|}{ Mean } & \multicolumn{3}{|c|}{ Standard Deviation } \\
\hline & & $\begin{array}{l}\overline{0} \\
\dot{\Xi} \\
\dot{\Xi}\end{array}$ & 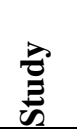 & है & $\begin{array}{l}\overline{0} \\
\dot{\Xi} \\
\dot{\Xi}\end{array}$ & 莺 & छै \\
\hline Somatic concern & Q1 & 2.31 & 3.09 & 2.4 & 1.453 & 1.792 & 1.5 \\
\hline Anxiety & $\mathrm{Q} 2$ & 2.24 & 4.80 & 3.3 & 1.647 & 1.986 & 1.8 \\
\hline Emotional Withdrawal & Q3 & 1.95 & 3.45 & 2.4 & 1.456 & 1.848 & 1.7 \\
\hline Conceptual Disorganization & Q4 & 2.09 & 4.11 & 2.9 & 1.302 & 1.970 & 1.9 \\
\hline Guilt feelings & Q5 & 1.93 & 3.21 & 2.4 & 1.183 & 1.796 & 1.6 \\
\hline Tension & Q6 & 2.21 & 4.18 & 3.0 & 1.321 & 1.936 & 1.9 \\
\hline Mannerism and posturing & Q7 & 1.98 & 3.68 & 2.6 & 1.304 & 1.738 & 1.7 \\
\hline Grandiosity & Q8 & 2.12 & 3.39 & 2.5 & 1.272 & 1.691 & 1.5 \\
\hline Depressive Mood & Q9 & 2.05 & 4.09 & 2.8 & 1.456 & 1.890 & 1.9 \\
\hline Hostility & Q10 & 2.02 & 3.66 & 2.7 & 1.000 & 1.871 & 1.7 \\
\hline Suspiciousness & Q11 & 2.07 & 3.73 & 2.7 & 1.375 & 2.093 & 1.9 \\
\hline Hallucinatory Behaviour & Q12 & 2.05 & 3.32 & 2.5 & 1.191 & 1.749 & 1.6 \\
\hline Motor Retardation & Q13 & 1.91 & 3.20 & 2.4 & 1.113 & 1.872 & 1.6 \\
\hline Uncooperative ness & Q14 & 2.03 & 3.16 & 2.4 & .917 & 1.886 & 1.5 \\
\hline Unusual thought content & Q15 & 2.24 & 3.13 & 2.5 & 1.247 & 1.936 & 1.6 \\
\hline Blunted Effect & Q16 & 2.00 & 3.86 & 2.8 & .973 & 1.958 & 1.9 \\
\hline Excitement & Q17 & 2.21 & 4.75 & 3.2 & 1.620 & 2.108 & 2.3 \\
\hline Disorientation & Q18 & 2.17 & 4.00 & 2.8 & 1.286 & 2.089 & 1.9 \\
\hline
\end{tabular}

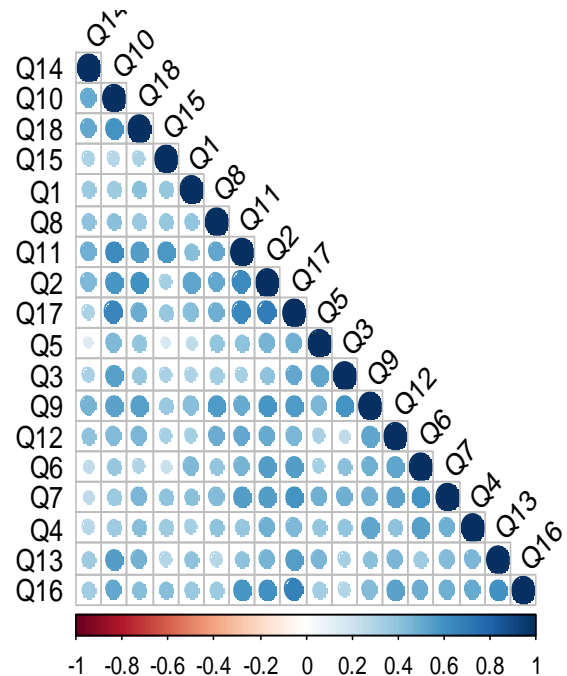

Fig. 1: Correlations between various items of BPRS

Table 4: SSCT- Frequency Table for the Total Scores of the 'Control' and the 'Study' groups

\begin{tabular}{|l|l|l|l|}
\hline Sl. No. & Score & Control Group & Study Group \\
\hline 1 & $<=6$ & 25 & 4 \\
\hline 2 & $7-12$ & 33 & 16 \\
\hline 3 & $13-18$ & 0 & 19 \\
\hline 4 & $19-24$ & 0 & 11 \\
\hline 5 & $25-30$ & 0 & 6 \\
\hline 6 & $>30$ & 25 & 4 \\
\hline
\end{tabular}


Table 5: Item-wise- Descriptive Statistics $(\mathrm{N}=116)$ for 'Control', 'Study' and the Combined groups

\begin{tabular}{|c|c|c|c|c|c|c|c|}
\hline \multirow[t]{2}{*}{ Attribute } & \multirow[t]{2}{*}{ Area } & \multicolumn{3}{|l|}{ Mean } & \multicolumn{3}{|c|}{ Standard Deviation } \\
\hline & & 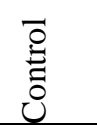 & $\begin{array}{l}\vec{a} \\
\stackrel{\vec{D}}{n} \\
\stackrel{n}{n}\end{array}$ & हే & $\begin{array}{l}\overline{0} \\
\text { 苛 } \\
\end{array}$ & $\begin{array}{l}\vec{D} \\
\stackrel{\vec{D}}{n}\end{array}$ & हี \\
\hline Father & A1 & 0.224 & 1.724 & 0.97 & 0.421 & 1.105 & 1.12 \\
\hline Mother & A2 & 0.552 & 0.741 & 0.65 & 0.502 & 0.849 & 0.70 \\
\hline Family & A3 & 0.293 & 0.638 & 0.47 & 0.496 & 0.765 & 0.67 \\
\hline Attitude & A4 & 0.345 & 0.931 & 0.64 & 0.479 & 0.856 & 0.75 \\
\hline Heterosexual & A5 & 0.362 & 0.793 & 0.58 & 0.488 & 1.022 & 0.83 \\
\hline Friend & A6 & 0.672 & 0.914 & 0.79 & 0.543 & 0.823 & 0.70 \\
\hline Superiority & A7 & 0.672 & 1.138 & 0.91 & 0.473 & 1.034 & 0.83 \\
\hline People & $\mathrm{A} 8$ & 0.448 & 0.448 & 0.45 & 0.502 & 0.753 & 0.64 \\
\hline Colleagues & A9 & 0.448 & 0.345 & 0.40 & 0.535 & 0.715 & 0.63 \\
\hline Fear & A10 & 0.689 & 1.983 & 1.34 & 0.503 & 1.051 & 1.05 \\
\hline Guilt & A11 & 0.552 & 2.931 & 1.74 & 0.502 & 1.122 & 1.48 \\
\hline Own & A12 & 0.672 & 1.759 & 1.22 & 0.473 & 0.979 & 0.94 \\
\hline Past & A13 & 0.483 & 0.638 & 0.56 & 0.504 & 0.718 & 0.62 \\
\hline Future & A14 & 0.362 & 0.638 & 0.50 & 0.488 & 0.831 & 0.69 \\
\hline Area-Goal & A15 & 0.483 & 1.069 & 0.78 & 0.538 & 1.041 & 0.88 \\
\hline
\end{tabular}

Table 6: AISS- Frequency Table for the 'Control' and the 'Study 'groups

\begin{tabular}{|l|c|c|c|}
\hline S. No. & Score & Control Group & Study Group \\
\hline 1 & $0-5$ & 0 & 0 \\
\hline 2 & $6-12$ & 18 & 1 \\
\hline 3 & $13-21$ & 40 & 18 \\
\hline 4 & $22-30$ & 0 & 29 \\
\hline 5 & $31 \&$ above & 0 & 10 \\
\hline
\end{tabular}

Table 7: SASS-Frequency Table for the total scores of 'Control' and 'Study' groups

\begin{tabular}{|l|c|c|c|}
\hline S. No. & Score & Control Group & Study Group \\
\hline 1 & $-6-1$ & 0 & 4 \\
\hline 2 & $-1-4$ & 0 & 0 \\
\hline 3 & $4-9$ & 0 & 10 \\
\hline 4 & $9-14$ & 0 & 20 \\
\hline 5 & $14-19$ & 0 & 17 \\
\hline 6 & $19-24$ & 0 & 4 \\
\hline 7 & $24-29$ & 0 & 2 \\
\hline 8 & $29-34$ & 58 & 1 \\
\hline
\end{tabular}

\section{Results and Discussion}

The burden of mental disorders worldwide is a major public health problem that affects patients, society, and nations as a whole. The impact of parental psychiatric disorder on children is not included routinely in medical education, but previous study by Taylor, D. C. (1985) ${ }^{7}$ suggested that context and background of patients' sickness should be considered to avoid misdiagnosis of childhood maladjustment and disorders. Considering the findings of GHQ for both groups (Table 1) are not significantly different, which in turn means that there is no effect of parental mental illness on general health of their offspring.

Brief Psychiatric Rating Scale (BPRS) ${ }^{8}$ test is used to assess the positive, negative and affective symptoms of individuals with psychiatric disorders (Table 2, 3 and Fig. 1). This instrument is particularly useful for assessing the efficacy of diagnosis \& treatment in case of patients with moderate to severe psychiatric disorder. ${ }^{\text {[9] Individual }}$ psychiatric characteristics of BPRS, it is found that the mean scores of study are higher than control groups and values are showing that the adolescent offspring (Study group) are more disturbed (Table 2 and Fig. 1) which is consistent with previous studies, (Manning \& Gregoire, 2006, 2009). ${ }^{10}$ Christiansen H. et al. (2019), ${ }^{11}$ which states that parental mental illness has been shown to affect attachment formation and the cognitive, emotional, social and behavioural development of children and are at increased risk of developing psychiatric disorder in childhood, adolescence and in later adult life. Also, another study confirms through applying modelling by including parental and family factors, 
the social environment, parent child interaction and possible child outcomes and concluded that adolescent children of parents with a mental illness are at an increased risk to develop disorders. Correlation matrix between all the items of BPRS (Fig. 1) was obtained and found that excitement is significantly correlated with anxiety, hostility and suspiciousness. There is significant correlation between other items also; however, some items like uncooperativeness and guilt are not correlated. This result is in accordance with a previous study that the items of the BPRS-18 can be grouped in clusters or factors, each one comprising a set of items that correlate highly among themselves, but associate little with the remaining items. ${ }^{10}$ As far as their interpersonal relations are concerned by using SSCT, area- wise analysis (Table 4 \& 5) that the Study group is carrying / projecting interpersonal conflicts with special reference to father, superiors at work or school, peer, guilt-goal (self-area) reflected is consistent with the finding based on alcoholism have a significant impact on the most basic operations of the family especially on adolescent such as lack of communication, increased conflict \& isolation from the community. ${ }^{12}$ As far as their interpersonal relations are concerned by using SSCT, areawise analysis reveals that the study group is carrying or projecting interpersonal conflicts with special reference to father, superiors at work or school, peer, guilt and goal (selfarea) reflected is consistent with the finding based on alcoholism have a significant impact on the most basic operations of the family especially on adolescent such as lack of communication, increased conflict $\&$ isolation from the community (Table 5). ${ }^{13}$ AISS inventory is designed to be an aid in counselling school students of age group 14-18 years whose personal problems are pertaining emotional, social \& educational adjustment. A large-scale study ${ }^{14-16}$ found the association between symptoms of mental illness in parents and emergence of emotional, social \& behavioural problems in children and between 10-15 year which is confirmed from the results obtained here using tool AISS, where the adolescents of parents with mental illness are having adjustment problems which is ranging from average to very unsatisfactory adjustment's score (Table 6).

Present investigation has tried to compare the attitude of these affected adolescents from the offspring adolescents of parents without mental disorders. A Sodhi Attitude Scale for Students (SASS) has been applied for assessment of their attitude in five areas namely in attitude towards parents and teachers, discipline, life and humanity, country and religion $\&$ found that the control group does not have any problems regarding their attitude in above respective areas which is consistent with the previous studies Bhave (1974) ${ }^{17}$ \& Chakraborty $(1982)^{18}$ that suggested attitude of students towards life and humanity showed positive and significant relation with country and religion. Significant positive correlation was found between attitude towards country and religion. While the Study group is showing attitudinal problems in the areas of discipline and humanity (Table 7). In the other areas like attitude towards parents, there is no difference while in areas of discipline, humanity and religion, the attitude of Study group is affected. According to the study
Deepshikha, B. $(2015)^{19}$ that one needs to change negative attitude to positive attitude of offspring towards their afflicted parents.

Here after going through the findings related to the psychological disturbances among adolescent offspring in relation to their general health, psychiatric disturbances, inter-personal relations within family and outside, adjustment capacities at emotional, social and educational level, adolescents' attitude towards their teachers-parents, discipline, life and humanity, country and religion, were showing significant difference between the two groups except on GHQ-12, where there is no difference between both the groups. It shows both the group differ in relation to psychiatric disturbance, interpersonal relation within and outside family, at adjustment capacity (emotional, social \& educational) and too in their attitude towards their teachersparents, discipline, life, humanity, country and religion. As far as their general health is concerned it reveals that parental mental illness doesn't impact the well-being of these adolescents. No where the impacts of gender \& socioeconomic status could be found.

\section{Conclusion and Recommendation}

This investigation has entertained the adolescent population by considering the fact that this population is marked by immense turmoil in emotional and behavioural spheres. ${ }^{20,21}$ The results of this study are highly encouraging. Based on the investigation objective related screening measures were used to detect the afflicted offspring from the total sample. General and psychological health, interpersonal relationship within and outside family and attitude towards parents, teachers, discipline, religion and country were assessed. The results have shown significant problem among the offspring of psychologically disturbed parent (Study) in comparison to the adolescent offspring of parents with normal well-being (control). Such findings are indicating the necessity of picking the vulnerable adolescents for further assessment under phase-II. The finding of this investigation is a matter of sensitization for parents with normal mental wellbeing, other family members, and society as whole to take care of this neglected population. The vulnerability of the offspring with psychologically disturbed parents are required a timely support to protect them from developing psychological issues later in life. The policy and provision to take care for such population is a direct need of the time. To continue with the present theme with more number of parents with mental illness \& sufficient number of adolescent offspring may bring better results in this area. Early detection and early intervention as the basic positive psychology approach can be the priority for prevention and promotion of mental health and wellbeing for future research. Since the adolescent offspring of parents with mental illness after screening are showing psychological sensitivity therefore they are recommended to undergo detailed psychological assessment in order to rule out significant psychological pathology so that required help can be provided as early as possible. 


\section{Limitations}

Since this study was to be conducted under time bound condition so the number of mentally disturbed parents in the said period whose adolescent offspring were required to be included in the sample was left smaller. Initially off springs of Study group were found to be highly reserved and apprehensive. Therefore, number of sessions were applied to make them agreeable. The problem of uncooperativeness was reflected when these subjects (Study group) were taken for individual psychological testing and it was time consuming too, therefore they were persuaded further. Results could not establish gender wise findings because of incompatible number of the availability of the subjects.

\section{Funding}

Self funded.

\section{Conflicts of interest}

None.

\section{References}

1. Mc Laughlin KA, Gadermann AM, Hwang I, Sampson NA, Al-Hamzawi A, Andrade LH, et al. Parent psychopathology and offspring mental disorders: results from the WHO World Mental Health Surveys. Br J Psychiatry 2012;200(4):290-9.

2. Frasquilho D, Matos MG, Salonna F, Guerreiro D, Storti CC, Gaspar T, Caldas-de-Almeida JM. Mental health outcomes in times of economic recession: a systematic literature review. BMC Public Health 2015;16(1):115.

3. Anant Shoshani \& Sarit Steinmetz, Positive Psychology at School: A School based Intervention to promote adolescents' mental Health \& Well Being. J Happiness, Stud 2013 DOI 10.1007/s 10902-013-9476-1.

4. Jagdish Varma, Sandhya Nair, Jaishree Ganjiwale, Somshekhar Nimbalkar, Nikhil Kharod. Cross Cultural Adaptation, into Gujarati, of the English version, Strengths and Difficulties Questionnaire [Internet].2018 July [Cited December23, 2019];12(7):VM01-VM03. Available from: http://www.jcdr.net//back issues.asp?issn=0973709x \&year=2018\&month=July\&volume $=12 \&$ issue $=7 \&$ page $=\mathrm{VM} 01 \& \mathrm{id}=11840$ doi:10.7860/JCDR/2018/34087/11840

5. Malhotra S, Sahoo S. Antecedents of depression in children and adolescents. Indian Psychiatry J [serial online] 2018 [cited 2019 Dec 23];27:11-6. Available from: http://www.industrialpsychiatry.org/text.asp?2018/27/1/11/243 312

6. The ICD-10 Classification of mental and behavioural disorders. Diagnostic criteria for research. World Health Organization (WHO). Oxford university press. Delhi 1994.

7. Taylor, D. C. The sick child's predicament. Aust New Zealand J Psychiatry 1985;19(2):150-7.

8. Overall, J. E., \& Gorham, D. R. The Brief Psychiatric Rating Scale (BPRS): recent developments in ascertainment and scaling. Psychopharmacology bulletin. 1988.

9. Fulford D, Pearson R, Stuart B K, Fisher M, Mathalon D H, Vinogradov S, Loewy, R. L. Symptom assessment in early psychosis: The use of well-established rating scales in clinical high-risk and recent-onset populations. Psychiatry Res 2014;220(3):1077-83

10. Manning C, Gregoire A. Effects of parental mental illness on children. Psychiatry 2006;5(1):10-2.
11. Christiansen H, Anding J, Schrott B, Röhrle B. Children of mentally ill parents - a pilot study of a group intervention program. Front Psychol 2015;6:1494.

12. Crippa J A S, Sanches R F, Hallak J E C, Loureiro S R, Zuardi A W. Factor structure of Bech's version of the Brief Psychiatric Rating Scale in Brazilian patients. Braz J Med Biol Res 2002;35(10):1209-13.

13. What Are the Effects of an Alcoholic Father on Children? September 3, 2019 (https://americanaddictioncenters.org/alcoholismtreatment/alcoholic-father).

14. Master. R (1985) Psychiatry for Undergraduates; Copyright Roshen Sohrab Master, Printed in India by Office Management Services, Pune.

15. Shastri PC, Shastri JP, Shastri D. Research in child and adolescent psychiatry in India. Indian J Psychiatry 2019;52 Suppl S3:219-23. Available from:http://www.indianjpsychiatry.org/text.asp?2010/52/7/219 169235

16. Chester A, Elgar K. The mental health implications of maternal employment: Working versus at-home mothering identities. Aust J Advancement Ment Health 2007;13(12):1-9.

17. Bhave, V. (1974). Thoughts on education. (Ed.) Sarva Seva Sangh Parkashan, Rajghat.Varanasi-1.P-104.

18. Chakhaborty, P.R. Religion and Education. J Indian Educ 1982;8(3):33-9.

19. Deepshikha B. Attitude of senior secondary school children towards their teachers and parents. Int J Manag Soc Sci 2015;3(7):187-92.

20. Rambha Pathak and Ravi C Sharma et. al. Behavioural \& emotional problems in school going adolescents. Astralas Med $J$ 2011;4(1):15-21.

21. Rutter M, Graham P Chadwick \& Yule (1976), Adolescent Turmoil: Fact or fiction? J Child Psychol Psychiatry 1976;17(1):35-56.

22. Sinha AKP, Singh RP. Adjustment Inventory for School Students; English Version; National Psychological Corporation ; Agra; 1993.

23. Sacks J M, Levy S. Sacks Sentence Completion Test. 1950 Sacks, J. M., \& Levy, S. (1950). The Sentence Completion Test. In L. E. Abt \& L. Bellak (Eds.), Projective psychology: Clinical approaches to the total personality (p. 357-402). Alfred A. Knopf. https://doi.org/10.1037/11452-011

24. Sodhi T S. Sodhi Attitude Scale for Students; English/ Hindi Version; National Psychological Corporation; Agra; 2005. 